\title{
И.А. Макарова
}

\section{ОЦЕНКА ЭФФЕКТИВНОСТИ ЭКОЛОГИЧЕСКИХ НАЛОГОВ С ПОЗИЦИИ «ЗАГРЯЗНИТЕЛЬ ПЛАТИТ» В СКАНДИНАВСКИХ СТРАНАХ: МЕТОДИКА И РЕЗУЛЬТАТЫ ИССЛЕДОВАНИЯ}

\begin{abstract}
Рассмотрена методика, позволяющая ответить на вопрос: действительно ли в основе экологических налогов лежит приниип «загрязнитель платит». Методика была разработана странами Северной Европь в 2001-2003 г2. Она предполагает выделение пяти секторов экономики: первичного сектора, обрабатывающей промышленности, энергетики, сектора услуг, а также домашних хозяйств. Данный подход базируется на определении доли потребления энергии (или загрязнения) в каждом секторе экономики и соответствующей доли начисленных налогов на энергию (или налогов на выбросы загрязняюших вещчеств). На основании наличия или отсутствия соответствия между этими структурными показателями судится о том, выполняется ли принции «загрязнитель платит» или нет. Подобная методика может применяться к любым экологическим налогам при наличии соответствующих данных. В случае необходимости возможна и более детальная разбивка по отраслям. Преимущество методики заключается в том, что использование относительных показателей избавляет от необходимости учитывать влияние инфляции, что делает показатели сопоставимыми по годам без корректировки на уровень инфляции. Использование удельных показателей также позволяет проводить сравнения между различными странами при условии, что методика определения экологических налогов и структура экологических налогов у них одинаковые.

Ключевые слова: экологические налоги, энергетические налоги, приниип «загрязнитель платит», экологическая налоговая реформа, углеродный налог, налог на $\mathrm{SO}_{2}$, методика оценки эффективности экологических налогов, двойной дивиденд.
\end{abstract}

Использование экологических налогов было признано эффективным средством ограничения эмиссии вредных веществ в 80-е гг. ХХ столетия. Данные налоги рассматриваются как корректирующие, так как они нацелены на сокращение загрязнения. В соответствии с этой целью в основе экологических налогов лежит принцип «загрязнитель платит». Страны Северной Европы были одними из первых, кто начал применять экологические налоги и проводить «зеленые» налоговые реформы [1. С. 32]. Соответственно эти страны обладают богатым опытом, который может быть позаимствован Россией на пути экологизации налоговой системы и достижения устойчивого развития. К сожалению, Скандинавские страны и Россия мало сопоставимы по протяженности территорий и климату. Тем не менее по климату северные страны более схожи с отдельными регионами России, чем страны Западной Европы. Кроме того, Скандинавские страны имеют богатый опыт в области энергосбережения и охраны окружающей среды. Именно эти факторы повлияли на выбор Скандинавских стран в качестве объекта изучения зарубежного опыта в области использования экологических налогов.

В последнее время Россия проводит политику экологизации налоговой системы. Так, субъекты РФ с 2010 г. получили право на дифференциацию 
ставок транспортного налога в зависимости от экологического класса автомобиля. С 2011 г. акцизы на топливо стали дифференцироваться по классам, учитывающим экологическую безопасность используемого топлива [2. C. 219]. Кроме того, с 2012 г. был введен утилизационный сбор. Попрежнему взимается плата за негативное воздействие на окружающую среду, ставки которой периодически индексируются. Можно сказать, что процесс экологизации налоговой системы в России идет с некоторым отставанием от мировой практики. Поэтому изучение зарубежного опыта, касающегося принципов установления экологических налогов, оказывающих наименьшее искажающее воздействие на экономику, а также практики сбора и обработки информации для оценки экологической эффективности налогов поможет избежать ряд трудностей и ускорить процесс экологизации налоговой системы. Обзор зарубежной литературы [3-17] позволил найти методику, на основании которой можно судить о соблюдении основополагающего принципа построения экологических налогов «загрязнитель платит». Цель и задачи нашего исследования заключаются в изучении данной методики, обобщении результатов ее применения в Скандинавских странах, выявлении ее преимуществ и недостатков, а также принципов использования.

Традиционно анализ налогов начинается с оценки их взаимосвязи с ВВП и совокупными налогами. Страны Северной Европы имеют одни из самых высоких показателей, отражающих долю экологических налогов в процентах от общей суммы налогов и в процентах от ВВП. Эти показатели позволяют лишь судить о масштабах экологического налогообложения, но не позволяют судить о степени выполнении принципа «загрязнитель платит». В связи с этим в 2001-2003 гг. Скандинавскими странами был предпринят проект, в рамках которого была поставлена цель - выяснить, действительно ли загрязнитель платит в соответствии с осуществляемым объемом эмиссии или за загрязнение платят какие-то определенные группы пользователей. Для достижения этой цели была разработана специальная методика, суть которой заключалась:

1) в фокусировке внимания на налогах на энергию и налоге на $\mathrm{SO}_{2}$;

2) разбивке экономики по отдельным секторам;

3) расчете доли каждого сектора в общем объеме потребления энергии и доли каждого сектора в общем объеме начисленных налоговых платежей, связанных с потреблением энергии;

4) расчете доли каждого сектора в общем объеме загрязнения атмосферного воздуха выбросами $\mathrm{SO}_{2}$ и доли каждого сектора в общем объеме начисленных налоговых платежей, связанных с загрязнением воздуха.

Представленное исследование было направлено на установление связи между теми, кто использует энергию и загрязняет окружающую среду, и теми, кто платит налоги. В результате данного исследования в 2003 г. вышел итоговый отчет национальных статистических служб Норвегии, Швеции, Финляндии и Дании, посвященный энергетическим налогам, налогу на $\mathrm{SO}_{2}$ и их эффективности. Данные налоги рассматриваются как разновидность экологических налогов. Следует отметить, что энергетические налоги являются самыми доходными среди всех экологических налогов европейских стран. Значит, влияние этих налогов наиболее существенно сказывается на поведе- 
нии экономических субъектов. Это, пожалуй, одна из главных причин, которая привлекла внимание исследователей.

Первая встреча представителей статистических служб стран Северной Европы состоялась в августе 2001 г. Ее цель заключалась в том, чтобы скоординировать действия по разработке Европейской системы сбора данных по окружающей среде и инициировать согласование статистических данных в целях проведения сравнительных исследований. Одним из важных методологических вопросов анализа являлось то, как страны интерпретируют определение энергетических и экологических налогов, а также само определение налогов, платежей и сборов в Системе национальных счетов. Согласование статистических характеристик энергетических налогов включало в себя урегулирование вопроса: должны рассматриваться валовые или чистые налоги и как следует относиться к возврату налогов? И второй важный вопрос заключался в том, как распределить налоги между различными группами экологических налогов.

Важным моментом при подготовке данных к сравнительному анализу было изучение различий в методах начисления налогов и в налоговых структурах Скандинавских стран. Статистика по энергетическим налогам в этих странах собирается приблизительно одинаково. Наиболее распространенный способ расчета налогов на энергию по секторам состоит в умножении объема потребления различных энергоносителей в разрезе по секторам на соответствующие налоговые ставки.

В ходе анализа использовались определения и классификации экологических налогов, разработанные Евростатом. Это позволило проводить сравнительные исследования между различными странами с точки зрения налоговой структуры, налоговой базы и доходов. В соответствии с определением Евростата экологический налог - это налог, налоговая база которого есть физическая единица чего-либо, что, как уже доказано, имеет специфическое негативное воздействие на окружающую среду. В качестве налоговой базы может быть использован либо непосредственно показатель, измеряющий и фактически отражающий негативное воздействие на окружающую среду, либо какойто косвенный показатель, используемый в связи с тем, что пока нет технической возможности либо экономически нецелесообразно напрямую измерять вредное воздействие. Согласно этому определению именно налоговая база определяет, является ли налог экологическим.

Евростат выделяет четыре группы экологических налогов: энергетические (включая налог на $\mathrm{CO}_{2}$ ), транспортные, налоги на загрязнение окружающей среды (включая налог на $\mathrm{SO}_{2}$ ) и ресурсные налоги (исключая налоги на добычу нефти и газа). Налоговая база энергетических налогов определяется Евростатом как:

1) энергетические продукты или энергоносители, используемые для транспортных целей (неэтилированный бензин, этилированный бензин, дизельное топливо, другие энергоносители для транспорта);

2) энергоносители, используемые для стационарных целей (легкий сорт мазута, тяжелое дизельное топливо, природный газ, уголь, кокс, биотопливо, другие виды топлива для стационарного использования, потребление и про- 
изводство электроэнергии, потребление и производство услуг централизованного теплоснабжения).

Как видно из классификации, налог на $\mathrm{CO}_{2}$ принадлежит к числу налогов на энергию, а не на загрязнение, так как во многих странах он тесно связан с другими энергетическими налогами и его очень трудно отделить от них. Налог на $\mathrm{CO}_{2}$ был введен намного позже, чем классические энергетические налоги, и с другой, отличной от них целью. Энергетические налоги использовались в большинстве стран как фискальный инструмент, они были введены, чтобы обеспечить государство доходами. В свою очередь, налог на $\mathrm{CO}_{2}$ был введен в 90-х гг. ХХ в. в странах Северной Европы с целью сокращения выбросов $\mathrm{CO}_{2}$. Следует отметить, что в ходе обсуждения состава исследуемых показателей было решено помимо энергетических налогов включить в исследование и налог на диоксид серы, несмотря на то, что в соответствии с классификацией Евростата данный налог является не энергетическим, а налогом на загрязнение. Кроме того, было решено провести более детальный анализ энергетических налогов.

В соответствии с принятой методологией данные об энергопотреблении, применяемые в вышеупомянутом отчете, - это фактически используемая в отраслях и домохозяйствах энергия, получение которой приводит к выбросам загрязняющих веществ в атмосферу в результате сжигания топлива. Топливо, преобразованное в другую форму топлива или используемое в качестве сырья, не учитывается в данном анализе. Энергия биомассы также включается в рассмотрение.

В ходе исследования помимо домашних хозяйств (households) были выделены четыре сектора экономики: первичный сектор (primary sector) и обрабатывающая промышленность (manufacturing), энергетика (electricity, gas, etc.) и сфера услуг (service sector). Четыре страны - Швеция (Sweden), Норвегия (Norway), Финляндия (Finland) и Дания (Denmark) - объединились, чтобы собрать, привести в сопоставимый вид и осуществить сравнительный анализ отобранных данных. Объектом анализа были в основном данные, собранные за 1999 г., и отчасти данные за 1990-2001 гг. В проектном предложении было указано, что более основательному исследованию подлежит также 1998 г. наравне с 1999 г., но позже было решено сосредоточиться на данных за 1999 г. Это было связано с тем, что норвежская налоговая система изменилась в период между 1998 и 1999 гг. в связи с введением отдельно идентифицируемого налога на $\mathrm{CO}_{2}$. Эти изменения сделали норвежские налоги более похожими на налоги остальных северных стран, что облегчало их сопоставление и анализ. Разбивка данных по секторам была основана на NACE (КДЕС - Классификатор видов деятельности Европейского сообщества). Данные по отраслям агрегировались в соответствии со следующими категориями: первичный сектор (NACE 1-14), обрабатывающая промышленность (NACE 15-37), энергетика (NACE 40-41), сфера услуг (NACE 45-99).

Несмотря на то, что все Скандинавские страны на момент проведения исследования использовали национальную валюту, данные о налоговых платежах и ставках для приведения в сопоставимый вид были представлены в евро. При анализе экологической эффективности было решено не использовать абсолютные показатели, так как это затрудняло их сравнение, поскольку в 
странах наблюдались разные темпы инфляции. Вместо этого в анализе используются в основном относительные показатели, отражающие долю потребления энергии, загрязнения или уплаченных налогов в общей сумме соответствующих показателей. Этот прием позволяет избежать корректировки данных на инфляцию, поскольку знаменатель и числитель затронуты одинаковым уровнем инфляции.

Выше мы постарались осветить основные принципы методики оценки экологических налогов, а теперь обобщим результаты исследования. Как отмечалось уже, любой анализ налогов начинается с определения размера налоговых платежей относительно ВВП и общей суммы налогов. Энергетические налоги и налог на $\mathrm{SO}_{2}$ в процентном соотношении к ВВП представляют собой интерес как индикаторы значимости этих налогов в совокупной стоимости производства страны. Данный показатель позволяет осуществлять сравнения между странами (табл. 1).

Таблица 1. Доля налогов в ВВП, \%, 1999 г.

\begin{tabular}{l|c|c|c|c}
\hline \multicolumn{1}{c|}{ Доля налогов в ВВП, \% } & Швеция & Норвегия & Финляндия & Дания \\
\hline $\begin{array}{l}\text { Энергетические налоги (искл. } \\
\text { налог на } \mathrm{CO}_{2} \text { ) }\end{array}$ & 2,1 & 1,5 & 2,2 & 2,2 \\
\hline Налог на $\mathrm{CO}_{2}$ & 0,67 & 0,60 & 0,36 & 0,40 \\
\hline Налог на $\mathrm{SO}_{2}$ & 0,01 & 0,02 & - & 0,04 \\
\hline Общая сумма всех налогов & 2,78 & 2,12 & 2,56 & 2,64 \\
\hline
\end{tabular}

Источник: Energy Taxes in the Nordic Countries - Does the polluter pay? URL: http://www.scb.se/statistik/mi/mi1202/2004a01/mi1202_2004a01_br_mift0404.pdf

Уровень дохода от энергетических налогов (исключая налог на $\mathrm{CO}_{2}$ ) в процентах к ВВП практически одинаков в Швеции, Финляндии и Дании и составляет чуть больше $2 \%$, Норвегия имеет более низкий уровень $(1,5 \%)$. Уровень доходов от налога на $\mathrm{CO}_{2}$ ниже, а диапазон относительно шире. Швеция имеет самый высокий уровень доходов от этого налога $(0,67 \%)$, а Финляндия - самый низкий $(0,36 \%)$. Доходы от налогов на диоксид серы тоже очень отличаются по странам. Дания имеет самый высокий доход $0,04 \%$ от ВВП. В Финляндии нет налога на диоксид серы. Фискальная значимость налога на диоксид серы очень низкая в Скандинавских странах, но налог выступает в качестве меры по снижению выбросов. Общая сумма энергетических налогов самая высокая в Швеции $-2,78 \%$ от ВВП, а самая низкая доля в Норвегии - 2,12\% от ВВП.

Доля энергетических налогов в общей сумме налогов и социальных страховых взносах представляет собой определенный интерес, так как она показывает, насколько широко энергетические налоги используются в качестве инструмента формирования доходной части бюджета. Этот показатель отражает различные тенденции в странах Северной Европы. В Дании их доля увеличилась с 3,6 до 5,2\% с 1990 по 2001 г., что является самым значительным ростом в течение данного периода. Похожая тенденция прослеживается в Финляндии, показатель увеличился с 2,6 до 4,3\%. В Швеции доля налогов снизилась за этот период с 5 до 4,8\%. Это может быть объяснено ежегодным ростом уровня доходов от налогов и страховых взносов в целом. Кроме того, 
это можно объяснить значительным увеличением уровня налогов на доходы и богатство. Так, например, с 1999 по 2000 г. произошло увеличение доли налогов на доходы и богатство с 16 до 42,3\% [16. С. 19].

К сожалению, уровень энергетических налогов в общей величине налогов не отражает их эффективность как инструмента природоохранной деятельности. Экологическая эффективность энергетических налогов определяется не их долей, а уровнем ставок, наличием освобождений, льгот и правилами возмещения расходов. Об эффективности экологических налогов можно судить на основании сокращения уровня загрязнения окружающей среды, вызванного этими налогами, и на основании выполнения принципа «загрязнитель платит». В данной статье мы сфокусировали свое внимание только на втором критерии. Итак, рассмотрим результаты оценки энергетических налогов в соответствии с методикой, разработанной национальными статистическими службами Скандинавских стран, цель которой подтвердить или опровергнуть гипотезу о том, что экологические платежи уплачиваются в соответствии с принципом «загрязнитель платит».

Как уже было отмечено выше, с целью проведения анализа все отрасли были агрегированы в четыре группы, плюс во внимание были приняты домашние хозяйства.

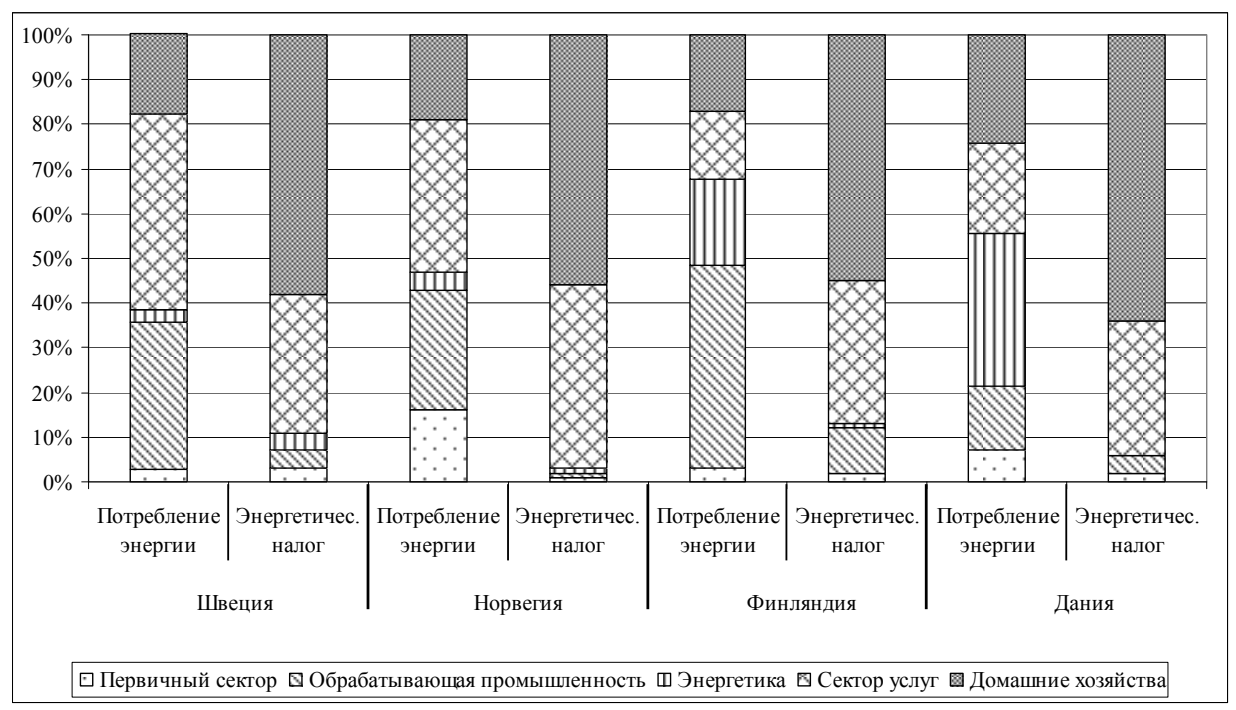

Рис. 1. Потребление энергии и доходы от энергетических налогов в \%, 1999 г. Источник: Energy Taxes in the Nordic Countries - Does the polluter pay? URL: http://www.scb.se/statistik/mi/mi1202/2004a01/mi1202_2004a01_br_mift0404.pdf

Рисунок 1 показывает в разрезе каждой страны: сколько энергии использует тот или иной сектор и как много энергетических налогов он платит. Бремя уплаты энергетических налогов распределено неравномерно между потребителями энергии. Это связано с налоговыми льготами и широко применяемым механизмом возврата энергетических налогов, которые использу- 
ются прежде всего в промышленности. Из рис. 1 видно, что уровень потребления энергии в обрабатывающем секторе колеблется от 14 до 45\% от его общей величины, в то время как энергетические налоги уплачиваются в диапазоне от 1 до 10\% от всей суммы энергетических налогов. Домашние хозяйства, напротив, используют от 17 до 24\% энергии, а уплачивают в диапазоне от 55 до 64\% энергетических налогов. Самое сильное отличие наблюдается в Дании, где домохозяйства используют 24\% энергии, а уплачивают $64 \%$ от всех энергетических налогов. Из этого анализа можно сделать вывод, что потребление энергии и поступления от энергетических налогов не согласованы таким образом, чтобы принцип «загрязнитель платит» выполнялся. Освобождения и механизм возврата налогов приводят к неадекватному распределению бремени расходов на потребление энергии. В результате расходы на потребление энергии и загрязнение ложатся прежде всего на домашние хозяйства.

Так как энергетические налоги довольно разнообразны, было принято решение о проведении более углубленного анализа того, кто использует энергию и кто действительно платит налоги. Для этого были выбраны налоги на электричество и бензин. Электричество было выбрано еще и потому, что это однородный продукт, который широко используется в Скандинавских странах. В табл. 2 показана фактическая налоговая ставка электроэнергии с разбивкой по различным отраслям. Северные страны очень отличаются по ставкам налога на электричество. Дания имеет самую высокую среднюю ставку налога на электроэнергию.

Таблица 2. Среднегодовые фактические налоговые ставки на электроэнергию, евроценты за 1 кВт/ч, 1999 г.

\begin{tabular}{l|c|c|c|c}
\hline \multicolumn{1}{c|}{ Показатели } & Швеция & Норвегия & Финляндия & Дания \\
\hline Все отрасли & 1,2 & 0,3 & 0,6 & 3,0 \\
\hline Домашние хозяйства & 1,8 & 0,6 & 0,7 & 6,2 \\
\hline $\begin{array}{l}\text { Сельское хозяйство и рыбо- } \\
\text { ловство }\end{array}$ & 0,7 & 0,6 & 0,7 & 0,0 \\
\hline $\begin{array}{l}\text { Разработка месторождений } \\
\text { полезных ископаемых }\end{array}$ & 0,2 & 0,2 & 0,4 & 0,1 \\
\hline Промышленное производство & 0,2 & 0,0 & 0,4 & 0,1 \\
\hline $\begin{array}{l}\text { Электро-, газо- и водоснабже- } \\
\text { ние }\end{array}$ & 1,9 & 0,1 & 0,0 & 0,0 \\
\hline Строительство & 1,8 & 0,8 & 0,7 & 0,0 \\
\hline Оптовая и розничная торговля & 1,8 & 0,7 & 0,0 & 0,3 \\
\hline Транспорт, хранение и связь & 0,8 & 0,6 & 0,7 & 2,3 \\
\hline Финансовое посредничество & 1,8 & 1,3 & 0,0 & 8,5 \\
\hline $\begin{array}{l}\text { Государственное управление и } \\
\text { услуги }\end{array}$ & 3,7 & 0,8 & 0,0 & 6,4 \\
\hline
\end{tabular}

Источник: Energy Taxes in the Nordic Countries - Does the polluter pay? URL: http://www.scb.se/statistik/mi/mi1202/2004a01/mi1202_2004a01_br_mift0404.pdf

Вариации ставок, представленные в табл. 2, свидетельствуют о том, что налоговая нагрузка не распределяется равномерно. Разнообразие фактических налоговых ставок отражает отличие в правилах изъятия налога, механизмах возврата и способах производства электроэнергии. Например, в Да- 
нии средняя ставка по всем отраслям выше, чем в других странах. Это отражает тот факт, что большая часть электричества производится здесь на основе ископаемого топлива.

На рис. 2 показано, сколько те или иные сектора экономики используют электричества и сколько они платят налогов за него. Общая тенденция заключается в том, что обрабатывающая промышленность использует значительную часть электроэнергии, но при этом не платит в соответствии с потребляемыми объемами. Налоговое бремя главным образом ложится на сектор услуг и домашние хозяйства.

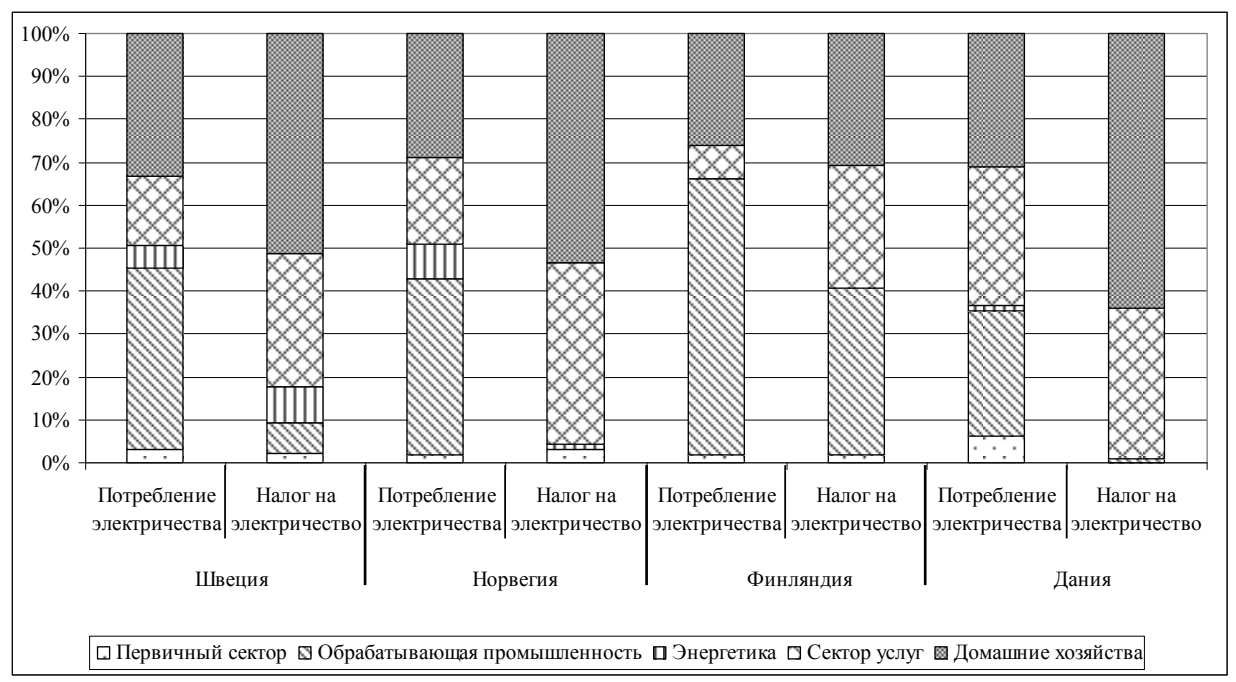

Рис. 2. Потребление электричества и доходы от налога на электричество, 1999 г. Источник: Energy Taxes in the Nordic Countries - Does the polluter pay? URL: http://www.scb.se/statistik/mi/mi1202/2004a01/mi1202_2004a01_br_mift0404.pdf

Как было отмечено выше, отличие налоговых платежей за электричество по Скандинавским странам может зависеть от способа производства электроэнергии: гидроэнергетика, ядерная энергетика и электростанции, работающие на ископаемом топливе. Разные способы производства порождают различные уровни загрязнения, и, следовательно, можно утверждать, что издержки загрязнения тоже меняются. Иначе дело обстоит с налогом на бензин. Его загрязняющее воздействие одинаково во всех странах. На рис. 3 показано, кто использует бензин, и кто платит соответствующий налог. При рассмотрении налога на бензин были использованы только две категории: все отрасли экономики (NACE 01-99) и домохозяйства.

Швеция имеет наиболее равномерное распределение между теми, кто использует бензин, и теми, кто платит налог на бензин, среди всех стран Северной Европы. Здесь предприятия используют 24\% от всего бензина и платят $25 \%$ от всех налогов. Эта небольшая разница может быть связана с погрешностями способа измерения. В Норвегии распределение налогового бремени между потребителями также относительно равномерное. Так, все отрасли 
экономики используют $25 \%$ бензина и платят $22 \%$ налоговых платежей. В Дании распределение менее равномерно, так как предприятия используют $27 \%$ бензина, а платят только $17 \%$ от налоговых платежей. Финляндия имеет еще менее сбалансированное распределение, так как все отрасли используют $51 \%$ бензина, а вносят только $35 \%$ от всех налоговых поступлений.

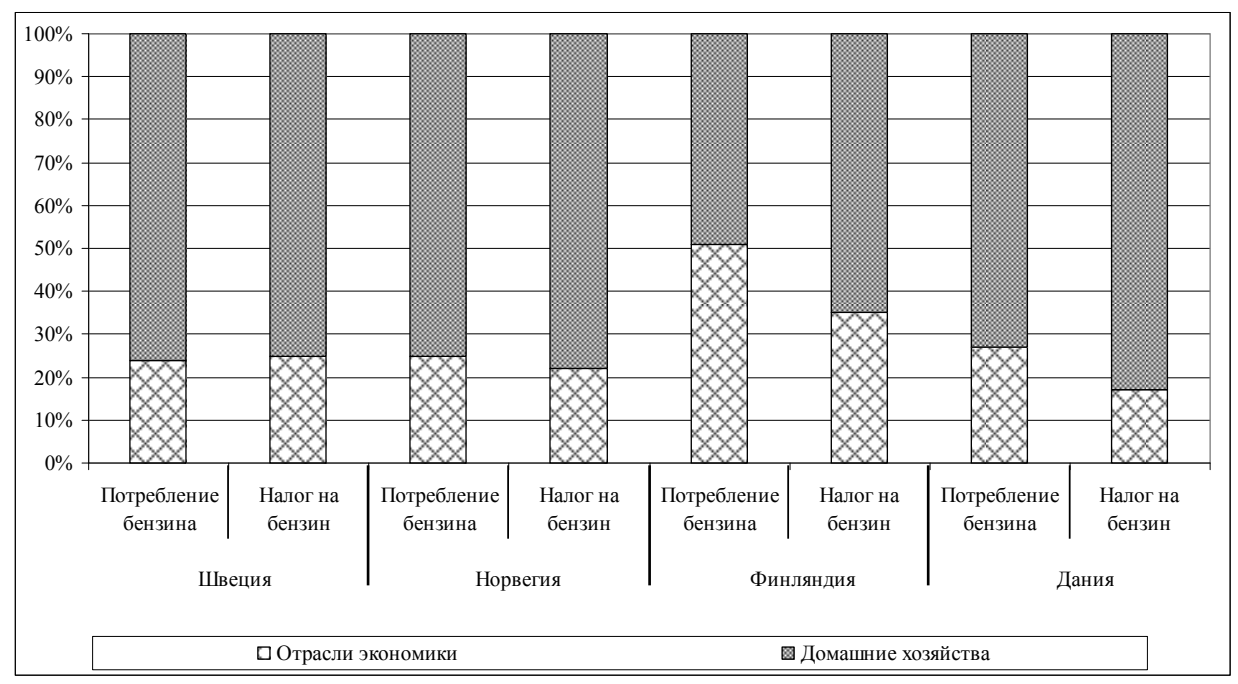

Рис. 3. Потребление бензина и налог на бензин, 1999 г.

Источник: Energy Taxes in the Nordic Countries - Does the polluter pay? URL: http://www.scb.se/statistik/mi/mi1202/2004a01/mi1202_2004a01_br_mift0404.pdf

Как уже было упомянуто, налог на $\mathrm{CO}_{2}$ был введен намного позже, чем классические энергетические налоги, и в связи с более специфичной, природоохранной целью. Эта цель способствует выдвижению гипотезы, что налог на $\mathrm{CO}_{2}$ в большей степени следует принципу «загрязнитель платит». Что же на самом деле? В табл. 3 показаны общий объем выбросов $\mathrm{CO}_{2}$ и общая сумма уплаченного углеродного налога в Скандинавских странах в 1999 г. Уровень выбросов $\mathrm{CO}_{2}$ колеблется от самого низкого уровня 52 млн т в Норвегии до самого высокого - 66 млн т в Швеции.

Таблица 3. Эмиссия $\mathrm{CO}_{2}$ и доходы от налога на $\mathrm{CO}_{2}$, в совокупности на душу населения и за тонну, 1999 г.

\begin{tabular}{l|c|c|c|c}
\hline \multicolumn{1}{c|}{ Показатели } & Швеция & Норвегия & Финляндия & Дания \\
\hline${\mathrm{Bceго} \mathrm{CO}_{2}, \text { млн т }}_{\mathrm{CO}_{2} \text { на душу населения, т/чел. }}$ & 66 & 52 & 58 & 65 \\
\hline $\begin{array}{l}\text { Общие доходы от налога на вы- } \\
\text { бросы } \mathrm{CO}_{2}, \text { млн } €\end{array}$ & 1508 & 818 & 454 & 652 \\
\hline $\begin{array}{l}\text { Доходы от налога на } \mathrm{CO}_{2} \text { на еди- } \\
\text { ницу выбросов } \mathrm{CO}_{2}, € / \mathrm{T}\end{array}$ & 23,0 & 15,6 & 7,8 & 10,0 \\
\hline
\end{tabular}

Источник: Energy Taxes in the Nordic Countries - Does the polluter pay? URL: http://www.scb.se/statistik/mi/mi1202/2004a01/mi1202_2004a01_br_mift0404.pdf 
Картина выглядит по-другому, когда выбросы рассматриваются относительно количества населения. Так, Дания и Норвегия имеют самые высокие относительные выбросы $\mathrm{CO}_{2}-12$ т на душу населения. У Швеции самый маленький уровень выбросов на душу населения (7 т). Уровни доходов от налогов на $\mathrm{CO}_{2}$ отличаются большим разнообразием. Швеция имеет самый высокий уровень поступлений от налога на $\mathrm{CO}_{2}$ (€1508 млн), а Финляндия - самый низкий (около €430 млн). Это различие в доходах главным образом объясняется более высокой ставкой налога в Швеции, как показывает анализ доходов на тонну.

Средняя величина налоговых доходов в расчете на тонну также демонстрирует значительное разнообразие по странам. Финляндия имеет ставку около $€ 8$ за тонну, Дания - $€ 10$, Норвегия - $€ 16$, в то время как в Швеции самый высокий уровень - 23 за тонну. Если сравнивать эти ставки с оценкой внешних издержек, которые вызваны выбросами $\mathrm{CO}_{2}$, то можно судить также о том, насколько данный налог является действительно корректирующим, экологическим налогом. Определение уровня налога на $\mathrm{CO}_{2}$ - это трудный вопрос. В свое время было проведено много исследований, которые дали различные результаты. Так, Общеевропейский проект ExternE исследовал ущерб от глобального потепления в 2002 г. Диапазон цен за тонну выбросов $\mathrm{CO}_{2}$ в рамках этого проекта был оценен между $€ 18$ и €46 (в ценах 1995 г.) в зависимости от предположений о диапазоне дисконтирования и стоимости капитала. Только средняя ставка налога на $\mathrm{CO}_{2}$ в Швеции в $€ 23$ за тонну выбросов соответствует расчетному уровню нанесенного ущерба согласно оценке, данной проектом ExternE.

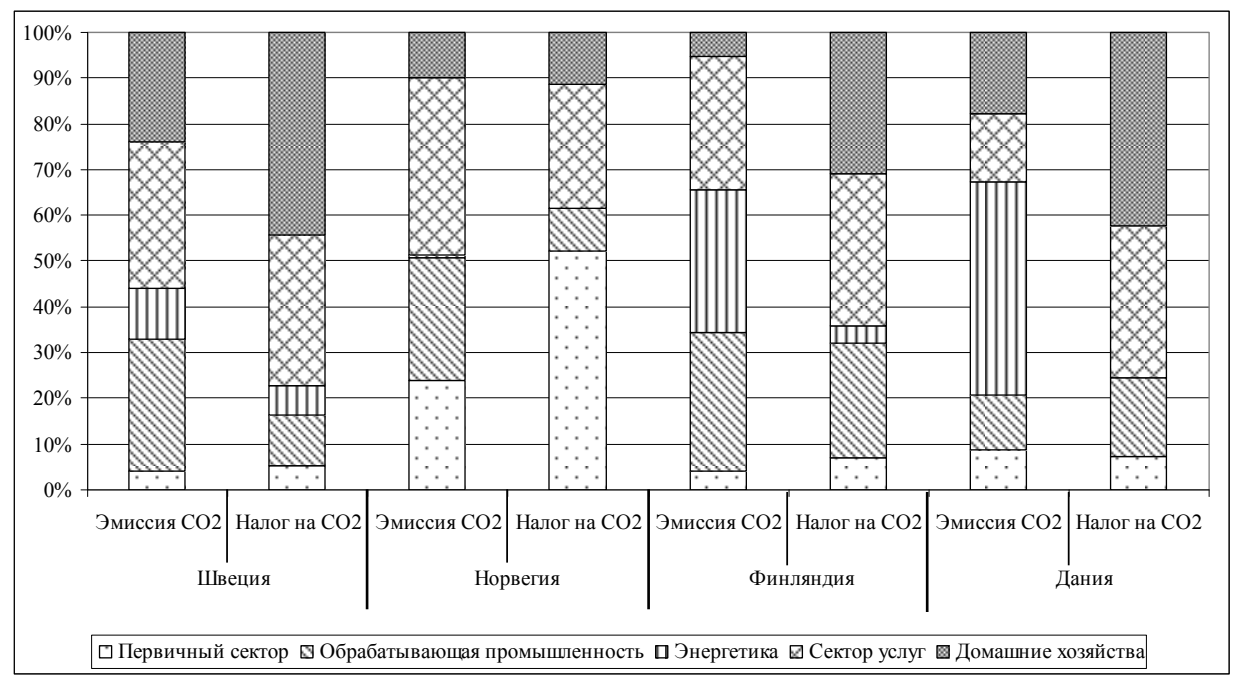

Рис. 4. Выбросы $\mathrm{CO}_{2}$ и поступления от налога на $\mathrm{CO}_{2}, 1999$ г.

Источник: Energy Taxes in the Nordic Countries - Does the polluter pay? URL: http://www.scb.se/statistik/mi/mi1202/2004a01/mi1202_2004a01_br_mift0404.pdf 
Теперь проверим, соответствует ли налог на диоксид углерода принципу «загрязнитель платит». На рис. 4 показаны доля выбросов $\mathrm{CO}_{2}$ и доля поступлений от налога на $\mathrm{CO}_{2}$ в разрезе установленных групп для каждой из четыpex стран. Самой значительной является разница в Дании, где энергетика имеет выбросы $\mathrm{CO}_{2}$ в размере $47 \%$, а платежи за этот объем эмиссии составляют $0 \%$ от всех налогов на $\mathrm{CO}_{2}$. В Швеции эмиссия диоксида углерода и платежи за него почти сбалансированы только в первичном секторе и сфере услуг. Что касается домашних хозяйств и обрабатывающей промышленности, то суммы отличаются почти в 2 раза. В Норвегии подобная картина наблюдается в первичном секторе и обрабатывающей промышленности. Зато в домашних хозяйствах эмиссия и платежи почти сбалансированы.

Теперь перейдем к рассмотрению доходов от налогов на серу (рис. 5).

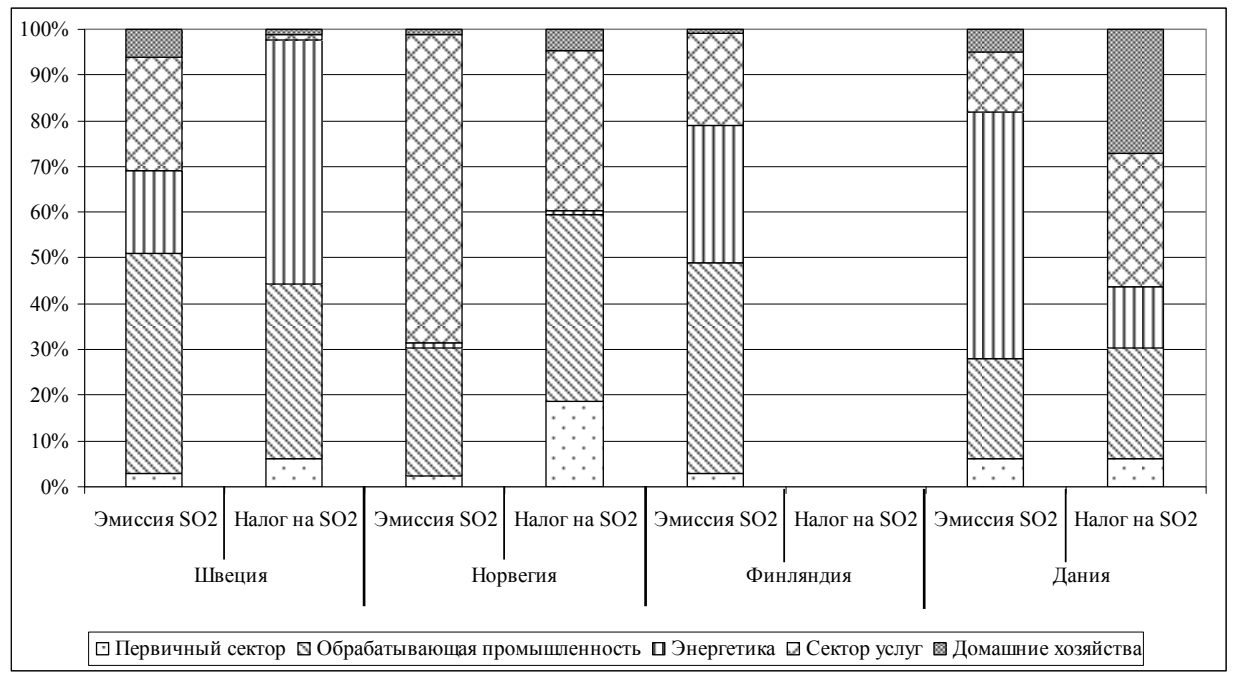

Рис. 5. Выбросы $\mathrm{SO}_{2}$ и поступления от налога на $\mathrm{SO}_{2}, 1999$ г.

Источник: Energy Taxes in the Nordic Countries - Does the polluter pay? URL: http://www.scb.se/statistik/mi/mi1202/2004a01/mi1202_2004a01_br_mift0404.pdf

Показатели, отражающие, кто фактически загрязняет окружающую среду и кто платит налог за выбросы $\mathrm{SO}_{2}$, сильно отличаются в Скандинавских странах. Различия происходят из-за того, что транспортировка и производство энергии освобождены от уплаты этого налога. Морской транспорт также приводит к большим объемам выбросов, но поскольку топливо для этих типов судов в основном приобретается в других странах, нет связи между использованием топлива и поступлениями от налога на $\mathrm{SO}_{2}$ в северных странах.

В Швеции топливо, используемое для судовых двигателей, освобождается от уплаты налога. Соответственно, сектор услуг, который эмитирует $25 \%$ $\mathrm{SO}_{2}$ в Швеции, платит только $1 \%$ от налогов на серу. Большинство выбросов в секторе услуг приходится именно на водный транспорт. Перерабатывающий сектор образует $48 \% \mathrm{SO}_{2}$, но на него возложено только $38 \%$ налогового 
бремени. Добывающий сектор, энергетика и домашние хозяйства платят более высокие доли налогов, чем их доли в общем объеме выбросов.

Что касается Норвегии, то налог на серу был введен здесь еще в 1970 г. Он стал первым природоохранным налогом Норвегии [17. С. 16]. Теоретически экологические налоги должны способствовать тому, чтобы рыночные цены в большей степени отражали социальные издержки экологически вредных видов деятельности и провоцировали сокращение последних. Что же на практике? Сектор услуг в Норвегии имеет самую высокую эмиссию $\mathrm{SO}_{2}$, и снова именно водный транспорт является основным источником выбросов в этом секторе. Сектор услуг выделяет 67\% выбросов, но платит только $35 \%$ налогов. Обрабатывающая промышленность, напротив, испускает 28\%, а платит 41\% налогов. Кроме того, добывающий сектор и домохозяйства платят большую долю налога на $\mathrm{SO}_{2}$, чем их доля в общем объеме выбросов серы. Большой объем выбросов и освобождения от налогов в транспортном секторе вызывают дисбаланс в других секторах.

В Дании в 1999 г. налог на выбросы серы взимался с электричества, а не непосредственно с топлива, используемого в энергетическом секторе. Это было изменено в 2000 г. В 1999 г. домашние хозяйства Дании имели выбросы $\mathrm{SO}_{2}$ в размере $5 \%$, но они платили $27 \%$ от всех налоговых поступлений. Налоги, уплачиваемые в секторе услуг, также высоки, что связано с налогами на выбросы $\mathrm{SO}_{2}$, взимаемыми с электроэнергии. Сектор услуг в Дании испускает $13 \% \mathrm{SO}_{2}$, а платит 29\% налогов. Наибольший вклад в объем выбросов данного сектора вносит водный транспорт. Энергетический сектор испускает $54 \% \mathrm{SO}_{2}$, но платит только 13\% налогов. Налог на серу не следует в полной мере принципу «загрязнитель платит», поскольку только в первичном секторе и перерабатывающей промышленности выбросы $\mathrm{SO}_{2}$ и платежи за них сбалансированы, чего нельзя сказать о домашних хозяйствах, энергетике и секторе услуг.

Итак, подведем итоги. Данная методика позволяет оценить, действительно ли в основе экологических налогов лежит принцип «загрязнитель платит». Другими словами, он позволяет судить о том, насколько эффективно формируются ценовые сигналы посредством экологических налогов. Следует отметить, что это не единственная методика, характеризующая экологическую эффективность налогов, но она имеет ряд преимуществ: 1) расчеты являются достаточно простыми; 2) показатели не испытывают влияния инфляции, что дает возможность легко осуществлять сравнения во времени; 3) использование удельных показателей позволяет осуществлять сравнения потребления энергии (или загрязнения) и соответствующих налоговых платежей между странами; 4) результаты применения данной методики четко детерминированы. Безусловно, использование данной методики требует значительной подготовительной работы, связанной с организацией соответствующей системы счетов, сбором данных и группировкой информации по секторам. Но такая работа сопровождает практически любое статистическое исследование. Данную методику можно дополнить факторным анализом, который показывает, как субсидии, налоговые льготы и другие факторы влияют на потребление природных ресурсов и загрязнение окружающей среды. 
Что касается оценки экологических налогов Скандинавских стран, то можно сказать, что они выявили низкую экологическую эффективность на 1999 г., так как основной принцип их установления «загрязнитель платит» выполнялся слабо. Если данный принцип не выполняется, значит, цены, определяемые отчасти этими экологическими налогами, дают некорректные сигналы экономическим субъектам. Те отрасли, которые широко пользуются налоговыми привилегиями, имеют слабые стимулы для того, чтобы инвестировать в энергосбережение и сокращение эмиссии загрязняющих веществ, и наоборот. Раз налоговое бремя не распределяется в соответствии с принципом «загрязнитель платит», значит, также нельзя говорить о том, что экологические налоги способствуют достижению устойчивого развития.

По результатам проведенного исследования разработчиками методики было рекомендовано странам Северной Европы: 1) ежегодно публиковать данные по налогам на энергию; 2) расширить свои расчетные системы, включив в них все экологические налоги, а не только налоги на энергию; 3) публиковать в дальнейшем информацию о субсидиях, полученных теми или иными секторами экономики. С нашей точки зрения, такую практику было бы полезно распространить и на другие страны, где активно используются экологические налоги. В России пока такая практика не ведется, хотя подобная методика может быть применима к плате за негативное воздействие на окружающую среду. В связи с большим перечнем загрязняющих веществ можно сначала сосредоточить внимание на нескольких основных загрязняющих веществах. Также методику можно применить к транспортному налогу и акцизам на бензин. Учитывая, что протяженность России очень большая и некоторые налоги являются региональными, анализ можно сделать и в разрезе регионов. Польза подобных статистических исследований заключается в том, что они могут обнаружить пробелы в инструментах регулирования деятельности хозяйствующих субъектов. Кроме того, данные исследования могут стимулировать изобретение новых средств или методов для преодоления трудных вопросов, касающихся использования экологических налогов как инструмента природоохранной деятельности.

В начале 1990-х гг. ряд экономистов утверждали, что возможно получение «двойного дивиденда», который связан с замещением отдельных искажающих налогов (например, на заработную плату) экологическими налогами. Они считали, что не только надлежащее сокращение загрязнения, т.е. не только экологические, но и экономические преимущества могут иметь место благодаря введению экологических налогов. Концепция двойного дивиденда и рост государственного долга в результате хронических бюджетных дефицитов подтолкнули многие страны к проведению «зеленых» налоговых реформ в 90-е гг. ХХ в. Посредством введения экологических налогов делались попытки решить не только экологические проблемы, но и проблемы безработицы и бюджетного дефицита. Практика показала, что у экологических налогов есть свои отрицательные результаты. Так, введение экологических налогов стало нередко приводить к экспорту загрязняющих веществ и «грязных» технологий в страны, где подобные налоги не использовались. С другой стороны, введение экологических налогов подрывало конкурентоспособность на мировом рынке тех отраслей, на которые возлагалось дополнительное нало- 
говое бремя. Это часто способствовало лоббированию интересов данных отраслей и получению ими освобождений, что, в свою очередь, усиливало искажающее воздействие экологических налогов на экономику страны.

Следует отметить, что достижение одновременно нескольких целей посредством экологических налогов - это очень сложный вопрос. Прежде всего необходимо все-таки определиться с приоритетом целей. На наш взгляд, экологические налоги все-таки должны в первую очередь стимулировать экономических субъектов к сокращению негативного воздействия на окружающую среду. Соответственно и конструироваться такие налоги должны исходя их принципов построения корректирующих налогов, а не доходообразующих налогов [18]. Построение доходообразующих и корректирующих налогов основано на разных принципах, поэтому совмещение этих целей, как правило, приводит к замещению экологической эффективности фискальной или экономической эффективностью. Как показал анализ, нередко интересы бизнеса стоят выше интересов домашних хозяйств, которые не имеют достаточных ресурсов, чтобы лоббировать свои интересы. В результате использования налоговых преференций экологические налоги становятся не столько корректирующими, сколько искажающими. Результаты данного анализа дают повод усомниться в концепции «двойного дивиденда».

В своей статье Ричард Моргенстерн отмечает, что пока в теории и политике сохраняется оптимизм относительно экологических налогов, в то время как новые исследования подчеркивают потенциальную значимость искажений, создаваемых экологическими налогами, и подрывают так называемую теорию двойного дивиденда. Данные исследования также свидетельствуют о том, что практически любая экологическая политика (прямое регулирование, налоги и переуступаемые разрешения) может усугубить уже существующие в экономике искажения. В настоящее время прямые экологические налоги (плата за единицу выбросов) используются ограниченно, в то время как косвенные экологические сборы (налоги на топливо, транспортные налоги) приобретают все большее значение в странах-членах ОЭСР [19. С. 3]. В целом неудивительно, что экологические налоги вызывают дополнительные искажения в экономике, так как при их моделировании не соблюдаются даже основные теоретические принципы, которые должны быть заложены в основу корректирующих налогов.

Часто зарубежными специалистами даются рекомендации о приоритетном использовании косвенных, а не прямых налогов, поскольку их легче организовывать и администрировать, они более эффективны с экономической точки зрения. Прямые же налоги требуют внедрения системы дополнительного контроля и постоянного мониторинга ситуации как со стороны государства, так и со стороны организаций. Для этого необходимы значительные дополнительные расходы и разработка новых технологий. Некоторые страны предпочитают на этом экономить. Учитывая современный уровень научнотехнического развития, большая часть проблем технического характера все же решаема. Другой вопрос, что не все предприятия хотят нести экологическую ответственность перед обществом. В этом случае их активность в данном направлении могут стимулировать как налоги, так и штрафы. В связи с этим интересен пример финской компании «Фортум», которая ввела в экс- 
плуатацию систему непрерывного мониторинга веществ в уходящих газах на трубах Челябинской ТЭЦ-2. Результаты мониторинга публикуются на сайте компании с 13 июля 2015 г. и доступны в онлайн-режиме любому пользователю Интернета [20]. Эта компания не только обеспечивает контроль над выбросами, но и предпринимает меры по очистке выходящих газов, чтобы они не превышали установленных предельно допустимых размеров.

В заключение отметим, что следующие статьи мы планируем посвятить применению данной методики в России, а также рассмотрению концепции «двойного дивиденда» и концепции экологической модернизации, так как проведение экологической налоговой реформы малоэффективно без долгосрочного структурного изменения модели производства и потребления. Ввиду серьезных экологических проблем, стоящих перед мировым сообществом в XXI в., экологическая модернизация как концепция имеет смысл только в том случае, если она используется как система координат, ориентир на более радикальные структурные изменения, которые способствуют экологической стабильности, а не экономической эффективности [21. С. 337].

\section{Лuтература}

1. Громов В.В. Перспективы экологизации налоговой системы Российской Федерации / В.В. Громов, Т.А. Малинина. М.: Издательский дом «Дело» РАНХиГС, 2015. 84 с.

2. Макарова И.А. Россия на пути экологизации транспортного и топливного налога // Вестн. Том. гос. ун-та. Экономика. 2015. № 4 (32). С. 212-223.

3. Ekins P. European environmental taxes and charges: recent experience, issues and trends // Ecological Economics. 1999. № 31. P. 39-62.

4. Kloke J. Ecological Tax Reform in Denmark: history and social acceptability / Jacob Kloka, Anders Larsenb, Anja Dahlc, Kirsten Hansen // Energy Policy. 2006. № 34. P. 905-916.

5. Kohlhaas M. Ecological Tax Reform In Germany: From Theory to Policy / Economic Studies Program Series. 2000. Vol. 6. URL: http://webdoc.gwdg.de/ebook/lf/2003/aicgs/publications/PDF/ecotax.pdf

6. Beuermann C. Ecological tax reform in Germany: handling two hot potatoes at the same time / C. Beuermann, T. Santarius // Energy Policy. 2006. № 34. P. 917-929.

7. Goulder H. Instrument Choice in Environmental Policy / Lawrence H. Goulder, Ian W.H. Parry. Discussion paper. 2008. 34 p. URL: http://www.rff.org/ files/ sharepoint/WorkImages/Download/RFF-DP-08-07.pdf

8. Repetto R. Green Fees: How A Tax Shift Can Work For The Environment And The Economy / R. Repetto, R.C. Dower, R. Jenkins, J. Geoghegan. 1992. 105 p. URL: http:// pdf.wri.org/greenfees_bw.pdf

9. Environmentally Related Taxes in OESD Countries: Issues and Strategies. 2001. 133 p. URL: https://www.cbd.int/financial/fiscalenviron/g-fiscaltaxes-oecd.pdf

10. Ptak M. Environmentally motivated energy taxes in Scandinavian countries // Economic and Environmental Studies. 2010. Vol. 10, No. 3. P. 255-269. URL: http://www.ees.uni.opole.p1/ content/03_10/ees_10_3 fulltext_01.pdf

11.Larsen H. Comments on the Discussion Paper. Conference on Environmental Fiscal Reform. Berlin, 27 June 2002. Prepared by Ministry of Taxation, Denmark. URL: http://www.oecd.org/env/ tools-evaluation/1935338.pdf

12.Nordic Tax Report 2014: electricity sector. Prepared by Nordenergi WG Taxes and Levies: A. Espensen, A. Kohopää, I. Pierre, I. Solberg. April 2015. URL: http://188.117.57.25/sites/default/ files/sk-15-nordenergi-tax-2014.pdf

13. Environmental Taxes: Implementation and Environmental Effectiveness Environmental Issues Series № 1. Copenhagen, 1996. URL: http://pure.au.dk/portal/files/56716306/ Env_taxes_ issue_report_no_1.pdf 
14. Environmental tax reform in Europe: implications for income distribution. EEA Technical report. 2011. № 16. URL: https://www.researchgate.net/ publication/269872781_Environmental_Tax_ Reform_in_Europe_Opportunities_for_the_future

15.Environmental Tax Reform in Europe: Opportunities for the future. Final report / S. Withana, P. Brink, A. Illes, S. Nanni, E. Watkins. 30 May 2014. URL: https:// ieep.eu/uploads/articles/attachments/84aa183b-9f81-4b00-a4d6-e93a14464252/ ETR_ in_ Europe_ _Final_report_of_IEEP_study___30_May_2014.pdf?v=63664509853

16. Energy Taxes in the Nordic Countries - Does the polluter pay? National Statistical offices in Norvay, Sweden, Finland \& Denmark. Final report. March 2003. URL: http://www.scb.se/ statistik/mi/mi1202/2004a01/mi1202_2004a01_br_mift0404.pdf

17. The Norwegian tax system - main features and developments. Chapter 2 of the budget proposal on taxes 2015. Oslo. 8 October 2014. URL: http:// www. statsbudsjettet.no/Upload/ Statsbudsjett_2015/dokumenter/pdf/chapter2_tax2015_eng.pdf

18. Макарова И.А. К вопросу о функциях и принципах экологического налога // Вестн. Том. гос. ун-та. Экономика. 2016. № 3 (35). С. 147-158.

19. Morgenstern $R$. Environmental Taxes: Dead or Alive? October 1995. URL: http://ageconsearch.umn.edu/bitstream/10595/1/dp960003.pdf

20.Мониторинг выбросов в атмосферу на Челябинской ТЭЦ-2. URL: https://purchase.fortum.ru/monitoring-vibrosov/?tube=0\&elements $=1400$

21.Andersen M.S. Ecological Modernization - Origins, Dilemmas and Future Directions / M.S. Andersen, I. Massa // Journal of Environmental Policy \& Planning. 2000. № 2. P. 337-345.

Makarova I.A., Department of Economics, Institute of Economics and Management, National Research Tomsk State University, (Tomsk, Russia).E-mail: Chivchish@mail.ru

\section{THE EFFECTIVENESS ASSESSMENT OF ENVIRONMENTAL TAXES FROM THE "POL- LUTER PAYS" POSITION IN THE SCANDINAVIAN COUNTRIES: THE METHODOLOGY AND RESULTS OF THE STUDY}

Keywords: environmental taxes, energy taxes, "polluter pays" principle, environmental tax reform, carbon tax, sulfur dioxide tax, effectiveness assessment methodology of environmental taxes, double dividend.

The paper considers a technique that allows to answer the question: are environmental taxes really based on the "polluter pays" principle? The methodology was developed by the Nordic countries in 2001-2003. It involves the allocation of five economy sectors: the primary, manufacturing, energy, services, and households ones. The approach is based on the calculating of the proportion of energy consumption (or pollution) in each economy sector and the corresponding proportion of accrued energy taxes (or taxes on pollutant emissions). The results of such manipulations, showing either correspondence or discrepancy between those structural indicators, can answer the question is the "polluter pays" principle being fulfilled. Such technique can be applied to any environmental taxes if there are adequate data. If necessary, more detailed breakdown by industries is possible. The advantage of the methodology is that the relative indicators usage delivers the need to take into account the inflation impact, so the indicators can be compared for years without adjusting for inflation. It also allows comparing data with different countries if the methodology for determining environmental taxes and its structure are the same.

\section{References}

1. Gromov V.V. Perspektivy ekologizatsii nalogovoy sistemy Rossiyskoy Federatsii / Gromov V.V., Malinina T.A. Moscow: Publishing house «Delo» Russian Academy of National Economy and Public Service, 2015. pp. 84.

2. Makarova I.A. Rossiya na puti ekologizatsii transportnogo i toplivnogo naloga // Bulletin of Tomsk State University. Economy. 2015. No. 4 (32). pp. 212-223.

3. Ekins P. European environmental taxes and charges: recent experience, issues and trends // Ecological Economics. 1999. № 31. pp. 39-62.

4. Kloke J. Ecological Tax Reform in Denmark: history and social acceptability / Jacob Kloka, Anders Larsenb, Anja Dahlc, Kirsten Hansen // Energy Policy. 2006. № 34. pp. 905-916. 
5. Kohlhaas M. Ecological Tax Reform In Germany: From Theory to Policy. Economic Studies Program Series. 2000. Vol. 6. URL: http://webdoc.gwdg.de/ebook/lf/2003/aicgs/publications/PDF/ecotax.pdf

6. Beuermann C. Ecological tax reform in Germany: handling two hot potatoes at the same time / Christiane Beuermann, Tilman Santarius // Energy Policy. 2006. № 34. pp. 917-929.

7. Goulder H. Instrument Choice in Environmental Policy / Lawrence H. Goulder, Ian W.H. Parry. Discussion paper. 2008. pp. 34. URL: http://www.rff.org/ files/sharepoint/WorkImages/ Download/RFF-DP-08-07.pdf

8. Repetto R. Green Fees: How A Tax Shift Can Work For The Environment And The Economy / R. Repetto, R.C. Dower, R. Jenkins, J. Geoghegan. 1992. pp. 105. URL: http:// pdf.wri.org/ greenfees_bw.pdf

9. Environmentally Related Taxes in OESD Countries: Issues and Strategies. 2001. pp. 133. URL: https://www.cbd.int/financial/fiscalenviron/g-fiscaltaxes-oecd.pdf

10. Ptak M. Environmentally motivated energy taxes in Scandinavian countries // Economic and Environmental Studies. 2010. Vol. 10. No. 3. pp. 255-269. URL: http://www. ees.uni.opole.pl/content/03_10/ees_10_3_fulltext_01.pdf

11. Larsen H. Comments on the Discussion Paper. Conference on Environmental Fiscal Reform. Berlin. 27 June 2002. Prepared by Ministry of Taxation, Denmark. URL: http://www. oecd.org/env/tools-evaluation/1935338.pdf

12. Nordic Tax Report 2014: electricity sector. Prepared by Nordenergi WG Taxes and Levies: A. Espensen, A. Kohopää, I. Pierre, I. Solberg. April 2015. URL: http:// 188.117.57.25/sites/default/files/sk-15-nordenergi-tax-2014.pdf

13. Environmental Taxes: Implementation and Environmental Effectiveness Environmental Issues Series № 1. Copenhagen 1996. URL: http://pure.au.dk/portal/files/ 56716306/Env_taxes_issue_report_no_1.pdf

14. Environmental tax reform in Europe: implications for income distribution. EEA Technical report. 2011. № 16. URL: https://www.researchgate.net/ publication/269872781_Environmental_Tax_ Reform_in_Europe_Opportunities_for_the_future

15. Environmental Tax Reform in Europe: Opportunities for the future. Final report / S. Withana, P. Brink, A. Illes, S. Nanni, E. Watkins. 30 May 2014. URL: https://ieep.eu/uploads/ articles/attachments/84aa183b-9f81-4b00-a4d6-e93a14464252/ETR_in_Europe_-_Final_report_of_IEEP study___30_May 2014.pdf? v=63664509853

16. Energy Taxes in the Nordic Countries - Does the polluter pay? National Statistical offices in Norvay, Sweden, Finland \& Denmark. Final report. March 2003. URL: http://www. scb.se/statistik/mi/mi1202/2004a01/mi1202_2004a01_br_mift0404.pdf

17. The Norwegian tax system - main features and developments. Chapter 2 of the budget proposal on taxes 2015. Oslo. 8 October 2014. URL: http://www. statsbudsjettet.no/Upload/Statsbudsjett2015/dokumenter/pdf/chapter2_tax2015_eng.pdf

18. Makarova I.A. K voprosu o funktsiyakh i printsipakh ekologicheskogo naloga // Bulletin of Tomsk State University. Economy. 2016. № 3 (35). pp. 147-158.

19. Morgenstern R. Environmental Taxes: Dead or Alive? October 1995. URL: http://ageconsearch.umn.edu/bitstream/10595/1/dp960003.pdf

20. Monitoring of emissions into the atmosphere at Chelyabinsk CHPP-2. URL: https:// purchase.fortum.ru/monitoring-vibrosov/?tube $=0 \&$ elements $=1400$

21. Andersen M.S. Ecological Modernization - Origins, Dilemmas and Future Directions / Andersen M.S., Massa I. // Journal of Environmental Policy \& Planning. 2000. № 2. pp. 337-345.

Makarova I.A. Ocenka ehffektivnosti ehkologicheskih nalogov s pozicii «zagryaznitel' platit» v skandinavskih stranah: metodika i rezul'taty issledovaniya [The effectiveness assessment of environmental taxes from the «polluter pays» position in the Scandinavian countries: the methodology and results of the study]. Vestnik Tomskogo gosudarstvennogo universiteta. Ekonomika - Tomsk State University Journal of Economics, 2017, no 40, pp. 124-140. 